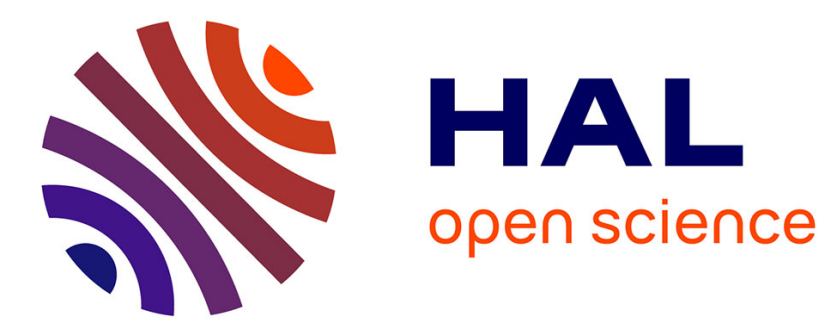

\title{
Optical absorption, photoconductivity and p-n junctions in cadmium telluride
}

\author{
B.M. Vul, V.S. Vavilov, A.F. Plotnikov, A.A. Sokolova, V.A. Chapnin
}

\section{To cite this version:}

B.M. Vul, V.S. Vavilov, A.F. Plotnikov, A.A. Sokolova, V.A. Chapnin. Optical absorption, photoconductivity and p-n junctions in cadmium telluride. Revue de Physique Appliquée, 1966, 1 (3), pp.217-221. 10.1051/rphysap:0196600103021700 . jpa-00242720

\section{HAL Id: jpa-00242720 https://hal.science/jpa-00242720}

Submitted on 1 Jan 1966

HAL is a multi-disciplinary open access archive for the deposit and dissemination of scientific research documents, whether they are published or not. The documents may come from teaching and research institutions in France or abroad, or from public or private research centers.
L'archive ouverte pluridisciplinaire HAL, est destinée au dépôt et à la diffusion de documents scientifiques de niveau recherche, publiés ou non, émanant des établissements d'enseignement et de recherche français ou étrangers, des laboratoires publics ou privés. 


\title{
OPTICAL ABSORPTION, PHOTOCONDUCTIVITY AND p-n JUNCTIONS IN CADNIUM TELLURIDE
}

\author{
By B. M. VUL, V. S. VAVILOV, A. F. PJOTNIKOV, \\ A. A. SOKOLOVA and V. A. CHAPNIN,
}

P. N. Lebedev Institute of Physics, Academy of Sciences, Moscow, USSR.

Résumé. - L'analyse des données expérimentales sur l'absorption optique, la réflexion et la photoconductivité du tellurure de cadmium indique une contribution considérable de l'absorption par exciton et du processus de la diffusion des excitons de la région superficielle dans le volume, suivie d'une dissociation.

Les durées de vie des porteurs en excès sont de l'ordre de $10^{-8}$ à $10^{-9} \mathrm{~s}$, aussi bien à faible qu'à forte excitation. On fournit des données sur les jonctions $p-n$ dans CdTe.

Abstract. - The analysis of the experimental data on optical absorption, reflection and photoconductivity of cadmium telluride indicates a considerable contribution of exciton absorption and the process of exciton diffusion from the surface region into the volume with subsequent dissociation.

The lifetimes of excess carriers are of the order of $10^{-8}-10^{-9} \mathrm{~s}$ both at weak and intensive excitation. The data on $p-n$ junctions in CdTe are presented.

Several years ago Yu. Masiakovets et al. in Leningrad have shown that CdTe photocells made by surface-barrier technique are promising for the purposes of solar energy conversion ( ${ }^{1}$ ). However, the difficulties of crystal growing and uncertain data en absorption mechanism, carriers' lifetime and mobilities have slowed down the progress of CdTe photocell utilization.

Optical absorption near the fundamental band edge in cadmium telluride crystals was studied by Davies and Shilliday [1] and Dubrovsky [2]. The results of the mentioned works do not agree.

The authors of [1] come to the conclusion that near the fundamental band edge the absorption is due both to direct and indirect transitions. According to [1] the absorption in the indirect region reaches $10^{3} \mathrm{~cm}^{-1}$. On the other hand, according to Dubrovsky's work, the intrinsic absorption is due only to incirect transitions. The results of electrical measurements and luminescence spectra [3] and the data on cyclotron resonance [4] indicate that in CdTe crystals the main part of absorption must be connected with the direct transitions. Marple and Segall, who studied the optical absorption in very pure cadmium telluride, came to the same conclusion [5].

The CdTe crystals used in the present work were grown by S. A. Medvedev and S. N. Maximovsky. The spectra of photoconductivity, absorption and reflexion were studied at liquid nitrogen or helium temperatures $\left({ }^{2}\right)$. The samples have $p$-type conduc-

(1) Yu. Maslakovets and oth., J. of Tech. Phys., USSR, 1957, 27, 1594.

(2) The methods of measurements will be given in detail in a paper submitted to Fizika Tuerdovo Tela.

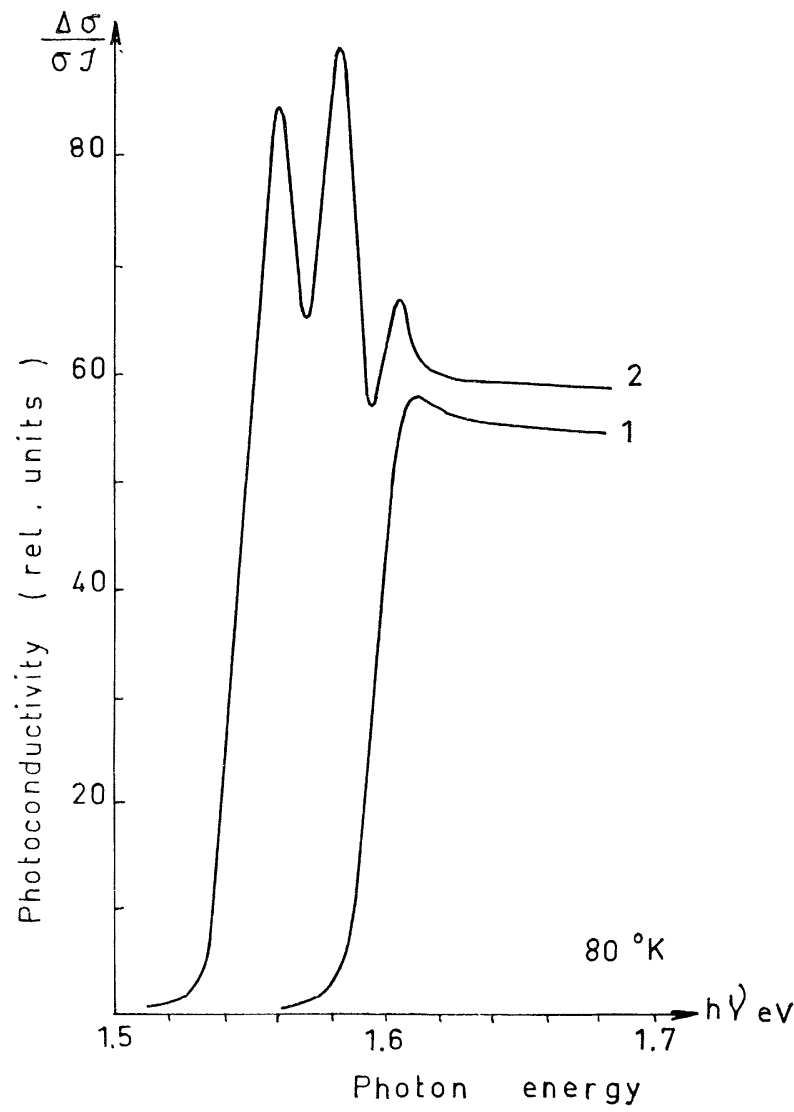

FIG. 1. - The photoconductivity of a CdTe sample with ground surface (curve 1) and strongly etched surface (curve 2) at $80 \mathrm{oK}$. 
tivity with hole concentrations of $10^{15}-10^{16} \mathrm{~cm}^{-3}$ at room temperature.

Figure 1 shows two typical photoconductivity spectra measured at $80^{\circ} \mathrm{K}$. The first curve is usual for samples with polished or sandblasted surfaces; its main feature is an extremely sharp increase of photoconductivity between 1,55 and 1,61 eV.

In the fundamental band region, the photoconductivity shows almost no dependence on absorbed photon energy. Photoconductivity is found only in the region of strong absorption, when almost all incident light is absorbed in a thin layer near the surface.

The photoconductivity spectrum of the second type (curve 2 on fig. 1) is observed, in the cases o cleaved or strongly etched surfaces. A typical feature of such spectra consists in three maxima at photon energies of 1,56 eV:1,583 eV and 1,605 eV. The energy difference between the photoconductivity maxima corresponds to the longitudinal phonon energy $(0,022 \mathrm{eV})$.

The energies of photons corresponding to two long-wave photoconductivity maxima are smaller than the forbidden gap width of $\mathrm{CdTe}$, equal to $1,595 \mathrm{eV}$ at $80^{\circ} \mathrm{K}[6]$. The oscillations of photo-

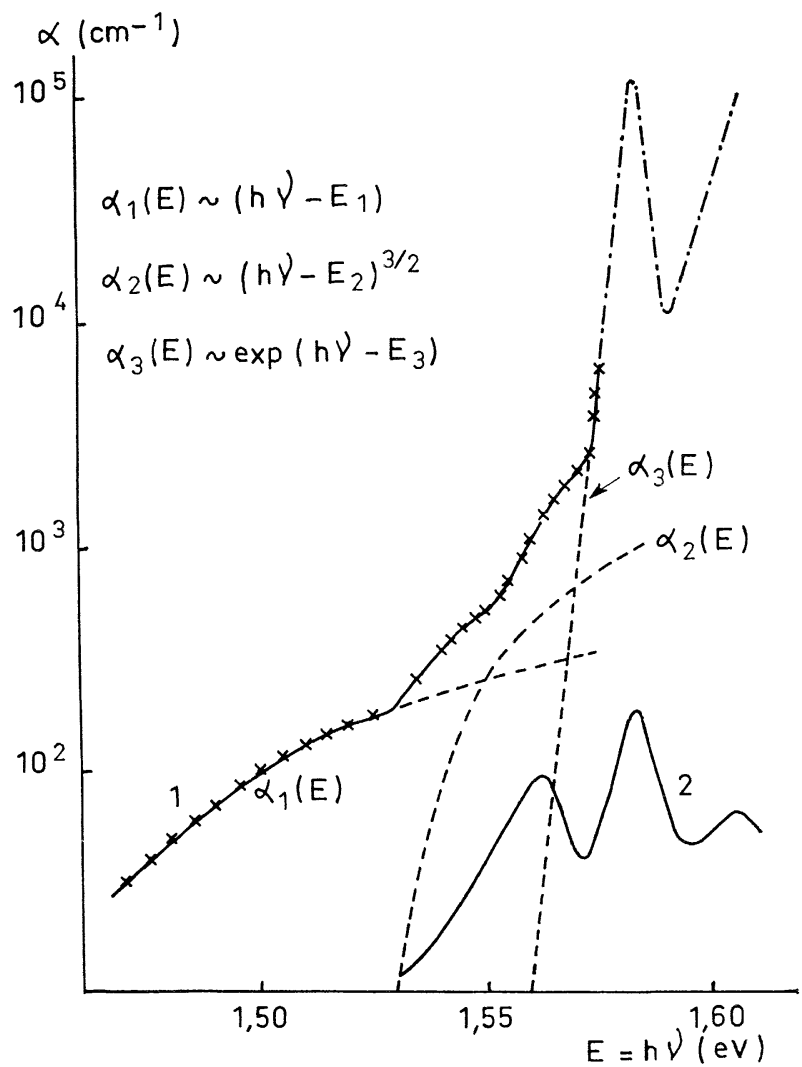

Frg. 2. - The absorption spectra (curve 1) and photoconductivity (curve 2) of CdTe at $80 \mathrm{oK}$. Broken lines represent separate components of the dependence $\alpha=f(h \nu)$ due to different absorption processes. conductivity cannot be explained by the mechanism suggested by H. Fan [7] for the intrinsic photoconductivity oscillations in $\mathrm{InSh}$ at $4 \mathrm{~K}$.

One could expect that the photoconductivity oscillations found in $\mathrm{CdTe}$ are connected with the oscillations of absorption.

To check this suggestion we have measured the absorption of identical CdTe crystals. A typical absorption spectrum is shown on Figure 2 by heavy line. One can see a structure in it. On the same figure are indicated the positions of photoconductivity maxima. It is seen that there exists a correspondence between the structure of both spectra. In the region of the second photoconductivity peak the absorption increases to a value that could not be determined even for thin samples $(\simeq 8 \mu)$. The absorption coefficient in this region was calculated from the data of reflectivity measurements. The spectral dependence of reflectivity $R$ is presented on Figure 3 (curve 1). The curve 2 on this figure again gives the spectrum of photoconductivity.

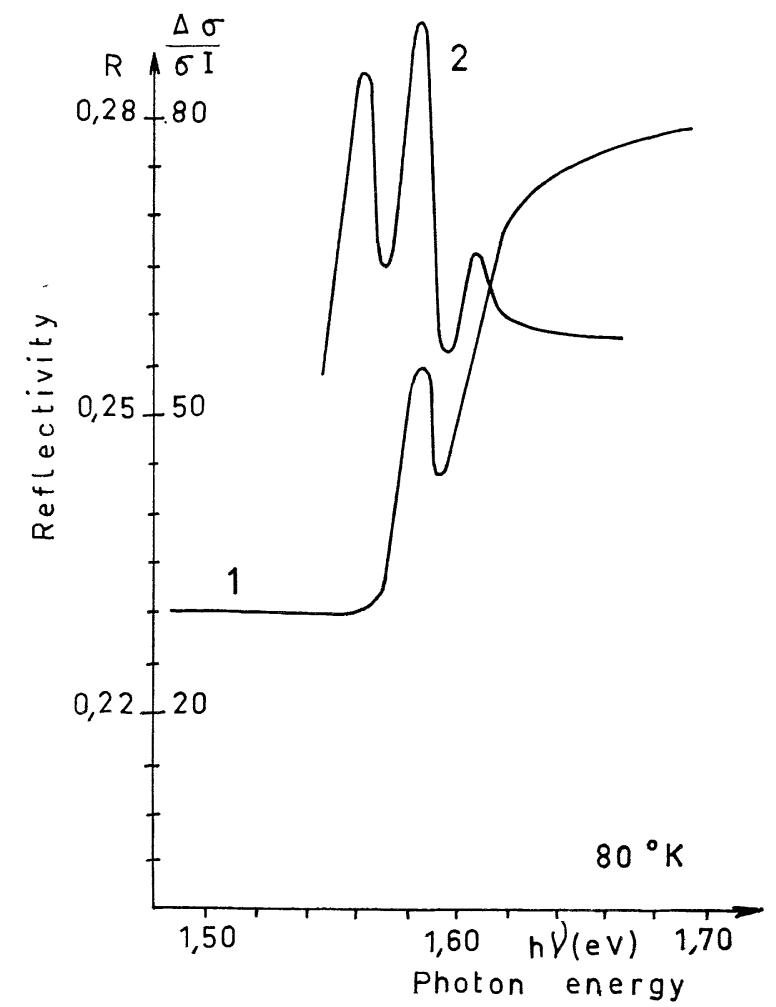

FIG. 3. - The reflectivity (curve 1) and photoconductivity (curve 2) of CdTe at $80^{\circ} \mathrm{K}$.

The position of narrow reflectivity peak coincides with the second photoconductivity maximum. The absorption coefficient, calculated according to the reflectivity data, reaches a peak value of about $10^{5} \mathrm{~cm}^{-1}$. It is hardly possible to explain the existence of such an absorption band by absorption due to defects or impurities. 
The local centres in semiconductors usually have absorption cross-sections of the order of $10^{-16} \mathrm{~cm}^{2}$ [8]. Thus, the absorption coefficient would reach a value of $16^{5} \mathrm{~cm}^{-1}$ only at the concentration of defects or impurities over $10^{20} \mathrm{~cm}^{-3}$. At such concentrations the shallow local levels form an impurity band merging with one of the energy bands of the crystals, and the narrow absorption band is improbable.

The existence of a narrow band of intensive absorption can be explained by exciton generation process. It is thought that the middle photoconductivity maximum $(h \nu=1,583 \mathrm{eV})$ is due to the dissociation of excitons generated in the crystal by incident light. The energy difference between the position of the middle photoconductivity maximum and the forbidden band width must correspond to the exciton binding energy. In our case, the observed difference is equal to $0,012 \mathrm{eV}$, i.e. practically equal to the reported binding energy of excitons in CdTe [9].

The long-wave photoconductivity peak can be explained by the dissociation of excitons generated by simultaneous absorption of photons and longitudinal optical phonons, and the short-wave maximum by the dissociation of excitons generated by absorption of higher energy photons with the emission of the same type of phonons.

If this suggestion is true, then the further decrease of temperature of the crystal must lead to the decrease and disappearance of the long-wave photoconductivity maximum. This effect was clearly observed experimentally. In Figure 4 is presented the photoconductivity spectrum, measured at $15^{\circ} \mathrm{K}$, of the crystal which at $80{ }^{\circ} \mathrm{K}$, had the spectral response shown in Figure 2 (curve 1). The width of the forbidden gap for CdTe at this temperature is near to $1,605 \mathrm{eV}$. According to this, the middle peak seen at $80^{\circ} \mathrm{K}$ is shifted to higher energy. The long-wave peak that was seen at $80^{\circ} \mathrm{K}$, disappears. One sees in the spectrum only the band connected with direct exciton generating transitions and with transitions including the emission of one, two and three optical longitudinal phonons.

According to the considerations mentioned above, we analyzed the spectral dependence of the absorption coefficient. The long-wave tail of curve 1 from Figure 2, that we shall denote as $\alpha_{1}\left(E_{1}\right)$ depends on energy $E=h \nu$ as $\alpha_{1}(E) \simeq\left(E-E_{1}\right)^{2}$. If we extrapolate this component to the middle part of the curve and determine for each value of $h \nu$ the difference between the total absorption coefficient and the value of $\alpha_{1}$, the difference can be described as $\alpha_{2}(E) \simeq\left(E-E_{2}\right)^{3 / 2}$.

The short-wave part of the absorption region, $\alpha_{3}(E)$ depends on photon energy nearly exponentially, as $\alpha_{3}(E) \simeq \exp \left(E-E_{3}\right)$. The sum of three components is given on Figure 2 by crossed dots and the separate components are shown by

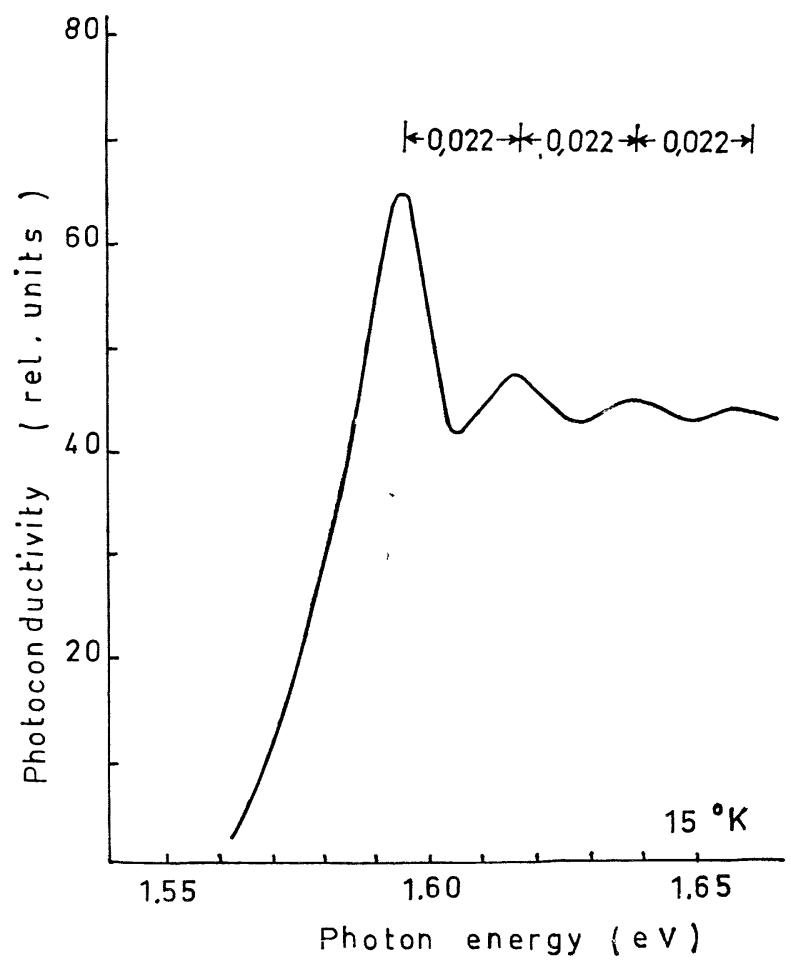

FIG. 4. - The structure of photoconductivity spectrum of CdTe at $15^{\circ} \mathrm{K}$.

interrupted lines. As it is known, the analysis of this type was first successfully used in the case of germanium by MacFarlane [10].

It seems to be natural to suggest, that in different regions of photon energies, the absorption of ligh ${ }^{+}$ is due to different processes. The dependence of the first type, $\alpha \simeq\left(E-E_{1}\right)^{2}$ is characteristic for the indirect interband transitions. If this is true, from experimental data of Figure 2 it follows that for CdTe this component of the absorption is rather insignificant. The largest absorption coefficient in this case is of the order of $100 \mathrm{~cm}^{-1}$ as compared with $10^{4} \mathrm{~cm}^{-1}$ in the region well inside the fundamental band. Thus, our results do not agree with the interpretation given in [1] and [2].

Elliott [11] has shown theoretically that in the case of indirect exciton absorption, the absorption coefficient has the $\left(E-E_{2}\right)^{3 / 2}$ type energy dependence.

Thus, the experimentally observed dependence of the type $\alpha_{2}(E) \simeq\left(h \nu-E_{2}\right)^{3 / 2}$ in the region of the long-wave photoconductivity peak does not contradict the suggestion that the absorption is due to indirect exciton transitions.

Finally, the dependence $\alpha_{0}(E) \simeq \exp \left(E-E_{3}\right)$ observed in the short wave part of the curve corresponds to the well known Urbach's rule [12]. Such dependence is typical for broad exciton absorption 
bands observed in ionic crystals in the region not close to the maximum. This dependence was explained theoretically by Toyozawa [13] and Mahr [14]. who suggested that the energy difference $\Delta E$ between the ground state and excited states depends strongly upon the positions of the ions surrounding the absorbing centre. Consequently, $\Delta E$ is determined by the lattice vibration types. Toyozawa suggested that the long-wave tail of the exciton absorption band in the case of direct transitions is determined by the interaction of absorption centre with longitudinal optical phonons, and calculated the absorption coefficient spectral dependence in the exciton band.

If $h \nu<h \nu_{0}$, where $h \nu_{0}$ corresponds to the exciton band maximum,

$$
\alpha(E) \simeq\left[\frac{1}{h \nu_{0}-h \nu}\right]^{1 / 2} \exp \left\{-\sigma\left(h \nu_{0}-h \nu\right)\right\}
$$

where $\sigma$ is a constant. For the conditions mentioned above, the energy dependence of $\alpha$ is nearly exponential.

Thus, the analysis of absorption by CdTe crystals leads to the same conclusions that followed from the photoconductivity spectra.

An exciton can dissociate as a result of interaction with lattice vibrations. This may explain the photoconductivity in the region of exciton band wavelengths. However, such a process does not explain the rolative intensities of photoconductivity maxima and their temperature dependence. The structure of the photoconductivity spectrum was observed in the region of rather strong absorption, in the case when excitons are generated with simultaneous phonon emission. We think that the appareance of photoconductivity maxima is due to the longer effective lifetime of carriers generated by excitons as compared to the carriers generated as a result of fundamental band absorption.

One of the possible reasons may be connected with the diffusion of undissociated excitons from the surface layer where the recombination rate is high towards the inner part of the crystal.

The electron-hole pair lifetimes in CdTe have been only roughly estimated. Lorenz, Segall and Woodbury indicate, that for undoped CdTe crystals the pairs' lifetime is near $10^{-8} \mathrm{~s}$. The lifetimes of pairs estimated according to the value of photoconductivity inside the fundamental band are of the same order. However, if we suppose that the carriers generated by the excitons' dissociation have the same lifetime, the estimate of the number of dissociated excitons gives a value larger than the number of absorbed photons. This is clearly meaningless ; consequently the lifetime of carriers generated by the exciton dissociation exceeds the lifetime of " usual " pairs of carriers.

This leads to the conclusion, that the photoconductivity is due not only to the thermal disso- ciation of excitons. It is thought to be connected to the " second order exciton collisions " suggested by Zhuse and Ryvkin [16].

According to their conception, the moving excitons interact with lattice imperfections with the result of exciton " semi decay", after which only one of the two carriers is transferred to the corresponding band. The second carrier is localized and does not contribute to the conductivity. It was shown experimentally that the exciton bands' photoconductivity is due to one type of carriers.

For the explanation of the relative intensity of the bands of " exciton photoconductivity" we have to take into account that in the crystals with polished or sandblasted surface there was no " exciton photoconductivity" in spite of the exciton generation. It is thought that in this case exciton annihilation prevails over the dissociation process.

In our laboratory there are used two types of rectifying junctions in $\mathrm{CdTe}$ both for studies of photocurrents and injection luminescence.

In the first case, $n$-CdTe samples are used as a base. Their carrier concentration at 300 \% is about $10^{14} \mathrm{~cm}^{-3}$ and their mobility reaches $1,2 \times 10^{3} \mathrm{~cm}^{2} / \mathrm{V} . \mathrm{s}$ at $300{ }^{\circ} \mathrm{K}$.

Aluminium has a shallow donor level with activation energy about $0,02 \mathrm{eV}$. At the decrease of temperature down to $80 \mathrm{oK}$, the electron concentration practically does not change. For the production of a $p$ - $n$ junction and non-rectifying contact, from one side we evaporated gold and from the other indium, and diffused them for a short time in vacuum. The direct current part of the VA-curve for these junctions gave the series resistance of about 50-100 ohm.cm that decreased at $80 \mathrm{o}$. The breakdown voltage reached $20 \mathrm{~V}$.

For the second type of $p$ - $n$ junctions, alloying process was used. $p$-type CdTe was used as a base. $p$-type CdTe was additionally heated in tellurium atmosphere. After this we obtained the hole concentration near $5.10^{16} \mathrm{~cm}^{-3}$ and the mobility about $50 \mathrm{~cm}^{2} / \mathrm{V} . \mathrm{s}$. $p-n$ junctions were made by indium alloying. The resistance in the forward direction had the same value as for the first type but increased at low temperature.

The density of excitation current required for stimulated emission at $80^{\circ} \mathrm{K}$ was near to $1 \mathrm{~A} / \mathrm{cm}^{2}$ at electron's energy of $150 \mathrm{keV}$. This corresponds to the estimate of the inverse populations' condition if the electron-hole pairs' lifetime exceeds $5 \times 10^{-9} \mathrm{~s}$. The energy yield of the stimulated emission at the excitation current density of $3 \mathrm{~A} / \mathrm{cm}^{2}$ and $80 \mathrm{~K}$ was near to $1 \%$. However, the stimu. lated emission flux increased with current density superlinearly and it is thought that for higher current densities the yield may reach several per cent.

The authors express their gratitude for the discussion and criticism of results, to L. V. Keldysh, 
N. A. Penin, V. N. Alamovsky, Yu. A. Kursky and M. V. Fock; for the cooperation in the experiments to V. D. Egorov, G. P. Golubev, V. S. Mashtakov. P. V. Shapkin and V. A. Chapnin.

\section{BIBLIOGRAPHY}

[1] Davis (P.) and Shilliday (T.), Phys. Res., 1960, 118, 1020 .

[2] Dubrovsky (G. B.), Fiz. Tyerd. Tela., 1961, 3, 1305.

[3] Segall (B.), Lorenz (M.) and Halsted (R.), Phys. Res., 1963, 130, 2471.

[4] Kanazawa (K.), Bull. Amer. Phys. Soc., 1963, 8, 620.

[5] Marple (D.) and Segall (B.), Bull. Amer. Phys. Soc., 1964, 9, 223.

[6] Thоmas (D.), J. Appl. Phys. (Suppl.), 1961, 32, 2298.

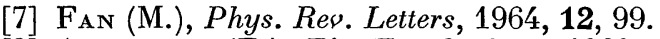

[8] Adrovich (E.), Fiz. Tuerd. Tela., 1960, 2, 22, 48.
[9] Halsted (R.), Lorenz (M.) and Segall (B.), J. Phys. Chem. Solids, 1961, 22, 109.

[10] MacFarlane (G.) et al., J. Phys. Chem. Solids, 1959, 8, 388.

[11] Eldiott (R.), Phys. Rer., 1957, 108, 1384.

[12] Manr (M.), Phys. Rev., 1962, 125, 1510.

[13] Toyozawa (Y.), Progr. Theor. Phys., 1958, $20,15$.

[14] Mahr (M.), Phys. Rev., 1963, 132, 1880.

[15] Lorenz (M.), Segall (B.) and Woodbury (A.), Phys. Res., 1964, 134, A 751.

[16] Zhuze (V. P.) and Ryvkin (S. M.), Izø. Akad. Nauk., Ser. Fiz., 1952, 16, no 1, 93. 